\title{
Analysis of the lethal interaction between the prune and Killer of prune mutations of Drosophila
}

\author{
Joe Biggs, Nick Tripoulas, Evelyn Hersperger, Charles Dearolf, ${ }^{1}$ and Allen Shearn ${ }^{2}$ \\ Department of Biology, The Johns Hopkins University, Baltimore, Maryland 21218 USA
}

The third-chromosome mutation Killer of prune (K-pn) causes no phenotype by itself, but causes lethality in individuals homozygous for the nonlethal X-chromosome mutation prune (pn). We have recovered 12 gammaray-induced revertants of Killer of prune. All of the revertants fail to complement a recessive cell lethal mutation in the abnormal wing discs (awd) gene. We present evidence that Killer of prune is a mutation in the awd gene. First, revertant $a w d^{K R 14}$ leads to reduced accumulation of the awd gene product, but does not affect flanking genes. Second, when a copy of the awd gene is cloned from Killer of prune homozygous flies and injected into embryos, transformants express the lethal interaction with prune. In individuals of the genotype $p n ; a w d^{K-p n} / a w d^{+}$the $a w d$ mRNA is present at normal levels but the awd polypeptide fails to accumulate. The absence of the awd gene product in such individuals is the cause of death. Although the awd polypeptide is a subunit of a cytoplasmic protein, its sequence is similar to subunit $\mathrm{V}$ of yeast cytochrome oxidase.

[Key Words: Cell lethal mutation; gene expression; gene interactions]

Received May 9, 1988; revised version accepted August 18, 1988.

Killer of prune $(K-p n)$ is a conditional dominant lethal mutation of Drosophila. It causes lethality only in individuals which are also homozygous or hemizygous for the eye color mutation prune (Sturtevant 1956). Otherwise, $K$-pn has no phenotype whether in the heterozygous or homozygous condition (Sturtevant 1956). Since prune is sex-linked and $K-p n$ is autosomal, all of the male progeny of a cross between homozygous prune females and homozygous $K$ - $p n$ males are lethal. Lifschytz and Falk (1969) took advantage of this selection system to recover revertants of $K$ - $p n$. They treated $K$-pn males with ethylmethane sulfonate (EMS) or X rays, mated them to prune females and recovered the rare male survivors. They found that all of the revertants were homozygous lethal and failed to complement each other. They believed the X-ray-induced revertants represented a set of deletions that overlapped in the region of $K$-pn, so the failure to complement for lethality could have been due to the deletion of vital genes surrounding $K$ - $p n$. They believed that the EMS-induced revertants represented a set of point mutations in a single gene, and the failure to complement for lethality was due to inactivation of that gene. Lifschytz and Falk further suggested that $K$-pn was a neomorphic or antimorphic mutation in this vital gene.

$K$-pn is located near the tip of the right arm of the third chromosome, close to the location of the abnormal

'Current address: Division of Chemistry and Chemical Engineering, California Institute of Technology, Pasadena, California 91125 USA.

${ }^{2}$ Corresponding author. wing discs $(a w d)$ gene (Dearolf et al. 1988a). The awd gene was identified by a lethal mutation, $a w d^{b 3}$. The wing discs of third-instar mutant larvae are small and have extensive areas of cell death; the brains and ventral ganglia of $a w d^{b 3}$ mutant larvae show extensive vacuolization. The awd gene has been isolated by transposon tagging (Dearolf et al. 1988b) and codes for a single mRNA of $0.8 \mathrm{~kb}$. This mRNA is transcribed in wing discs, brains, and ventral ganglia. The $a w d^{b 3}$ mutant gene does not make the normal transcript (Dearolf et al. 1988b). To confirm that it is a null allele, we obtained deletions of the awd gene to compare the phenotype of $a w d^{b 3}$ hemizygotes to that of homozygotes. Using the screen for revertants of $K$-pn devised by Lifschytz and Falk (1969), we recovered $12 \mathrm{~K}$-pn revertants, all of which were homozygous lethal. We hoped that at least one of the revertants would be a deletion that included the awd gene. Unexpectedly, all 12 revertants failed to complement the lethality of $a w d^{b 3}$. This suggested that $K-p n$ and $a w d^{b 3}$ were either two different mutations in the same gene or mutations in adjoining genes. Since we have cloned the awd gene, we were able to distinguish between these two possibilities. Our results indicate that $K-p n$ is a mutation in the $a w d$ gene.

\section{Results}

\section{Recovery of revertants}

From the cross of irradiated $K$-pn males to prune (pn) females (Fig. 1), we recovered 72,000 females and $35 p n$ males. Twelve of the 35 putative $K$-pn revertants were 


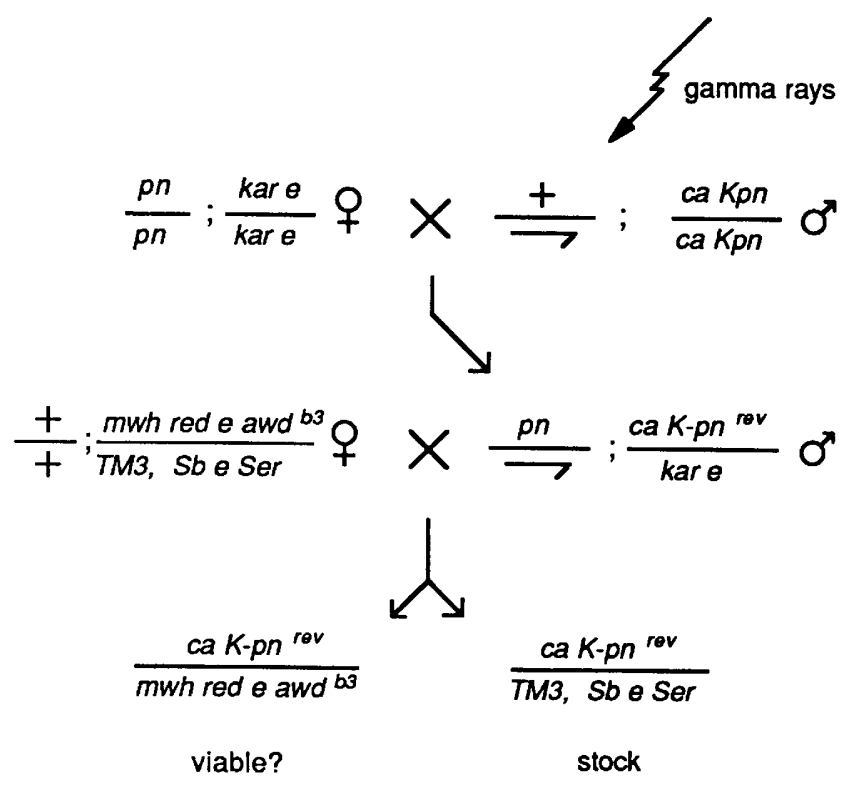

Figure 1. Screen for Killer of prune revertants. $K-p n / K-p n$ males were irradiated and mated to $p n / p n$ females. The only $p n$ hemizygous males recovered should be those which carry a revertant of the $K$-pn mutation. All fertile revertants were tested for complementation with the $a w d^{b 3}$ allele and maintained as balanced lethal stocks.

fertile. These revertants are all homozygous lethal. None of the 12 complement the lethality of $a w d^{b 3}$. Six of the revertants have been examined cytologically. Three have detectable chromosome aberrations in the 100C-D region of the third chromosome. One of the three, $a w d^{K R 21}$, is a large deletion which includes all of the 100C-D region (Fig. 2). The other three revertants $\left(a w d^{K R 7}, a w d^{K R 14}\right.$, and $\left.a w d^{K R 17}\right)$ have no detectable abnormalties in the 100C-D region.
Mapping the $\mathrm{K}$-pn revertants awd $\mathrm{dR}^{\mathrm{KR}}$, awd ${ }^{\mathrm{KR} 14}$, and awd $\mathrm{KR}^{\mathrm{K} 17}$

The three $K$-pn revertants without cytologically detectable abnormalities in the 100C-D region were examined for DNA rearrangements within the awd region. The results are shown in Figure 3 and diagramed in Figure 4. The awd gene in both control (mwh red e) and $K$-pn flies is contained in a $2.2-\mathrm{kb}$ PstI fragment, while the corresponding PstI fragment from the TM3 balancer chromosome is $2.4 \mathrm{~kb}$ in length (Dearolf et al. 1988b). Because of this polymorphism, changes in the 2.2 -kb PstI fragment from the $K$-pn chromosome are detectable in the DNA from heterozygous revertant flies with the genotype $a w d^{K R} / T M 3$. As shown in Figure 3A (lane 8) and more clearly in Figure 3B (lane 3), the 2.2-kb Pst fragment from the $K$-pn chromosome is missing in $a w d^{K R 7}$. Otherwise, the DNA fragments generated by restriction enzyme digestion of $a w d^{K R 7} / T M 3$ DNA appear identical to those found in $K$-pn/TM3 DNA. This lack of novel restriction fragments indicates that the whole region covered by the cloned DNA has been deleted in $a w d^{K R 7}$.

In $a w d^{K R 17}$, the 2.2-kb PstI fragment has been replaced by a fragment which is 0.8 -kb smaller (Fig. $3 \mathrm{~A}$, lane 10). The absence of the 2.2-kb fragment is shown more clearly on a lower-percentage agarose gel (Fig. 3B, lane 5). The 3.4-kb Sall fragment contains the $2.2-\mathrm{kb}$ Pstl fragment, and is also reduced by $0.8 \mathrm{~kb}$ to $2.6 \mathrm{~kb}$ (Fig. $3 \mathrm{~A}$, lane 5). Additional mapping data (not shown) indicated that the SacI site close to the 3' end of the awd gene was removed by the $a w d^{R R 17}$ deletion. The results localize the 0.8-kb deletion in $a w d^{K R 17}$ toward the $3^{\prime}$ end of the awd gene, as shown in Figure 4.

The initial whole genome Southern blots of $a w d^{K R 14} /$ TM3 DNA revealed no changes in the region of the awd gene (Fig. 3A, lanes 4 and 9). Since this revertant was generated by gamma rays and failed to complement the

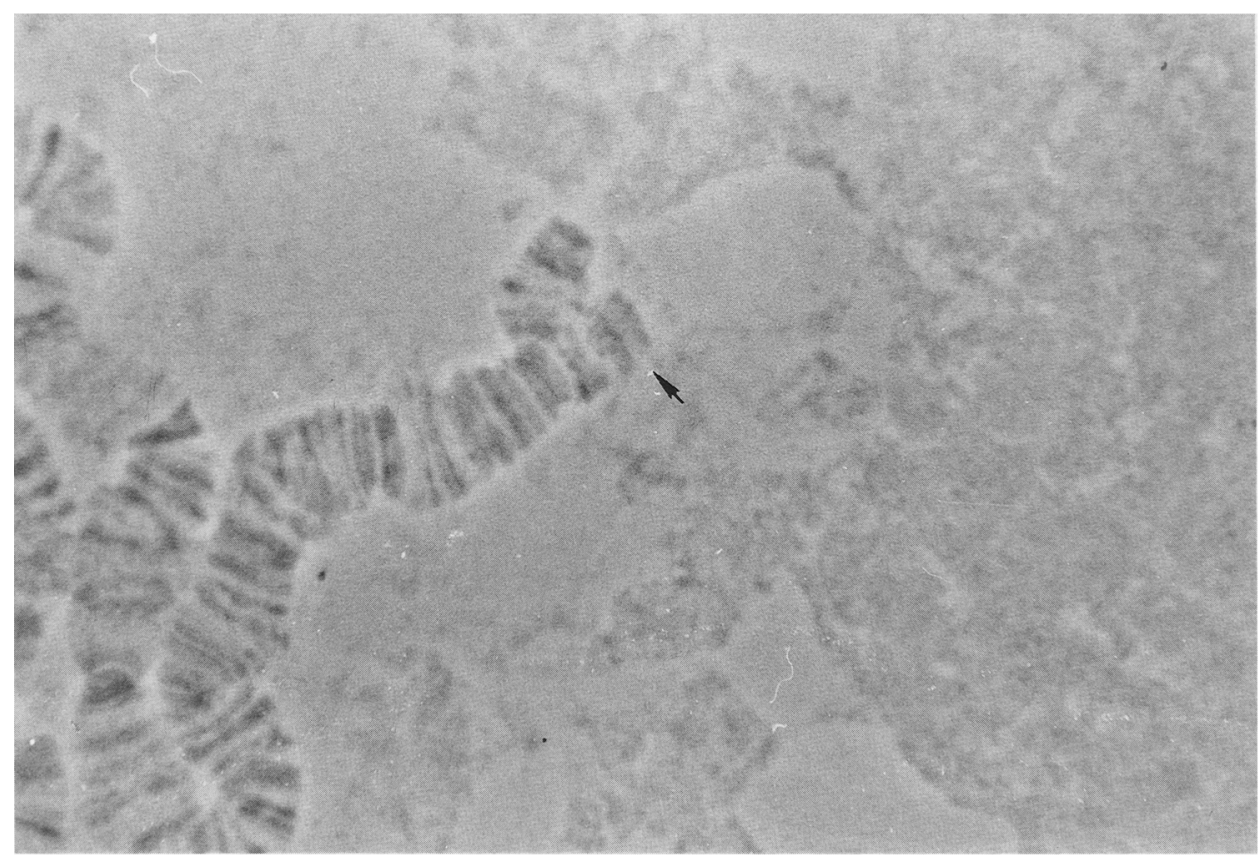

Figure 2. Salivary gland chromosomes from $a w d^{K R 21} /+$ larvae. The deletion of the 100C-D region is indicated by the arrow. 


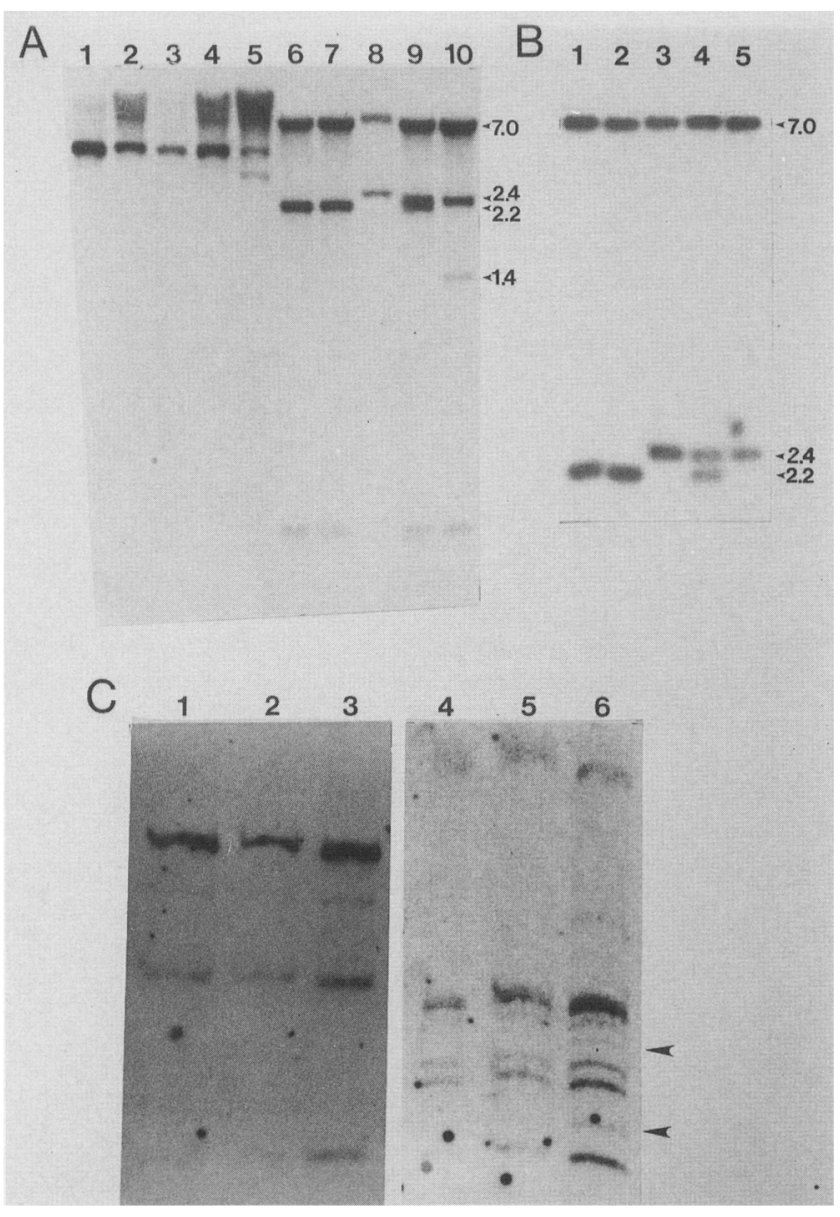

Figure 3. Analysis of $a w d^{K-p n}$ revertant alleles $a w d^{K R 7}$, $a w d^{K R 14}$, and $a w d^{K R 17}$ by whole genome Southern blots. DNA from adults was digested with SalI $(A$, lanes 1-5), PstI $(A$, lanes $5-10 ; B$, lanes $1-5\}$, or AluI $(C$, lanes $1-6)$. The digested DNA was fractionated on either a $1.5 \%$ agarose gel $(A)$, a $0.8 \%$ agarose gel $(B)$, or a $5 \%$ polyacrylamide gel $(C)$, and blotted (electroblotted for the $5 \%$ polyacrylamide gel) onto a nylon membrane. The membranes were hybridized to a radiolabeled 4.0-kb EcoRI-SacI fragment (probe 1, Fig. 4) containing the awd gene $(A$ and $B)$, to a radiolabeled awd cDNA $(C$, lanes $1-3)$, or to a radiolabeled fragment (probe 3, Fig. 4), from the awd 5'flanking sequence $(C$, lanes 4-6). Genomic DNA was made from adults which were $m$ wh red e/mwh red $e(A$, lanes 1,$6 ; B$, lane $1 ; C$, lanes 1,4); $a w d^{K-p n} / a w d^{K-p n}(A$, lanes 2,7; $B$, lane 2; $C$, lanes 2,5); $a w d^{K R T / T M 3}\left(A\right.$, lanes 3,$8 ; B$, lane $3 \mid$, $a w d^{R R 14} / T M 3$ $(A$, lanes 4,$9 ; B$, lane 4$) ;$ awdRR17/TM3 $(A$, lanes 5,$10 ; B$, lane 5$)$, or larvae which were $a w d^{K R 14} / a w d^{K R 14}(C$, lanes 3,6$)$.

lethality of $a w d^{b 3}$, some change in the awd gene must have occurred. To find this change, genomic DNA from mwh red e, K-pn, and $a w d^{K R 14}$ larvae was digested with AluI, which cuts at the tetranucleotide sequence AGCT. The DNA fragments were hybridized with either an awd cDNA or with probe 3 (Fig. 4) which contains $1.0 \mathrm{~kb}$ of nontranscribed DNA from the 5' side of $a w d$. As shown in Figure 3C (lane 3), there is no detectable difference between the $K-p n$ and $a w d^{K R 14}$ revertant DNA when probed with the awd cDNA, but when probed with the upstream sequence, two new bands appear in the $a w d^{K R 14}$ AluI digest (Fig. 3C, lane 6). This result suggests that a small deletion or an inversion is located in the 5 -nontranscribed region of the awd gene in this revertant.

Effect of K-pn revertants, awd $\mathrm{d}^{\mathrm{KR} 14}$ and awd ${ }^{\mathrm{KR} 17}$, on the accumulation of the awd gene transcript

To assess the effect of $a w d^{K R 14}$ and $a w d^{K R 17}$ on the transcription of awd and nearby genes, RNA was isolated from Canton-S, awd $d^{K R 14} / a w d^{K R 14}$, and $a w d^{K R 17} / a w d^{K R 7}$ third-instar larvae. The awd transcript is abundant at this stage in normal larvae (Dearolf et al. 1988b). The RNA was fractionated on an agarose gel, blotted onto a nylon membrane, then hybridized with a mixture of two cDNAs. One cDNA hybridizes to a $1.35-\mathrm{kb}$ transcript derived from a gene upstream of the awd gene; the other hybridizes to the $0.8-\mathrm{kb}$ awd transcript. The same filter was then rehybridized with probe 2 , which hybridizes to a $0.9-\mathrm{kb}$ transcript from a gene downstream of the awd gene (see Fig. 4 for probes utilized). The $1.35-\mathrm{kb}$ transcript is present in all three samples and serves as an indicator of the relative amount of RNA loaded in each lane. The level of the 1.35-kb transcript in awd $a w d^{K R 7}$ is one-half that of the others because $a w d^{K R 7}$ deletes the region which codes for that transcript. We used $a w d^{K R 17} / a w d^{K R 7}$ transheterozygotes in this experiment because a second mutation elsewhere on the $a w d^{K R 17}$ chromosome makes it impossible to get homozygous $a w d^{K R 17}$ third-instar larvae. The $0.8-\mathrm{kb}$ awd transcript is present in Canton-S RNA, but is missing in both $a w d^{K R 14} / a w d^{K R 14}$ and $a w d^{K R 17 / a w d^{K R 7}}$ RNA (Fig. 5A). The 0.9-kb transcript is absent in $a w d^{K R 17 / a w d K R 7}$, but is present at normal levels in $a w d^{K R 14} / a w d^{K R 14}$ (Fig. 5B). The only transcript missing from $a w d^{K R 14} / a w d^{K R 14}$ RNA is the awd gene transcript. The fact that reversion of the $K$-pn mutation occurred by eliminating the product of a single gene, the awd gene, implies that the K-pn mutation is an allele of the awd gene.

\section{Germ-line transformation}

We have used germ-line transformation to prove that $K-p n$ is an allele of awd. A genomic library was made by cloning DNA from $K$-pn homozygotes into the EMBL-4 vector (see Materials and methods). A phage containing the awd gene was isolated from this library by screening with the awd cDNA. A 3.4-kb SalI fragment was isolated from this phage, subcloned into the Carnegie 20 transformation vector, and injected into embryos according to the method of Rubin and Spradling (1982). The Carnegie 20 vector carries a ry ${ }^{+}$gene (Rubin and Spradling 1983). We used $r y^{+}$transformants with insertions on the $\mathrm{X}$ or second chromosome to demonstrate that the $K-p n 3.4-\mathrm{kb}$ Sall fragment rescues the lethality caused by $a w d^{b 3}$ (data not shown). We used a ry ${ }^{+}$transformant with an insertion on the third chromosome to demonstrate that this 3.4-kb Sall fragment is sufficient to cause the lethal interaction with prune. The genotype of this transformant is $x y^{506}\left[r y^{+} a w d^{K-p n}\right] / T M 3, r y^{506} e S b$. 
$3.4 \mathrm{~kb}$ Sal 1 fragment
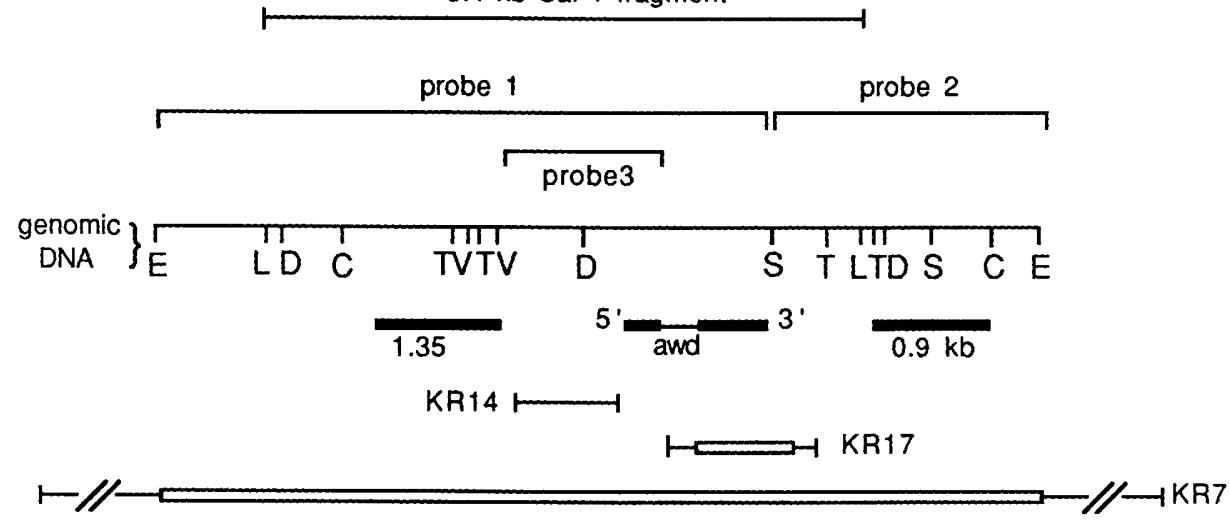

Figure 4. Map of deletions found in $K$-pn revertant DNA. The fine line represents genomic DNA, with restriction sites indicated for EcoRI (E), SalI (L), DraI (D), ScaI |C), PstI (T), PvuII (V), and SacI (S). The solid bars represent the awd transcript and flanking transcripts. The lower bars indicate the size and position of deletions found in $K$-pn revertant lines $a w d^{K R 7}, a w d^{K R 14}$, and $a w d^{K R 17}$. DNA fragments used as probes are shown at the top of the figure. The 3.4-kb Sall fragment, also shown at the top of the figure, is the fragment used for germ-line transformation.

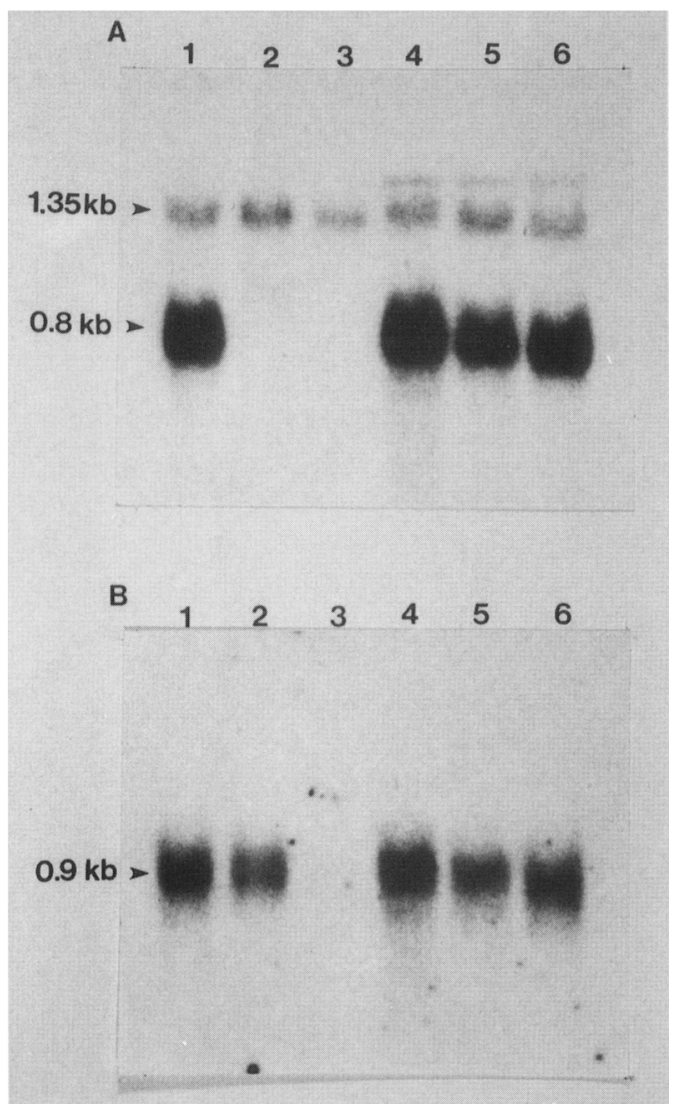

Figure 5. Total RNA isolated from third-instar larvae was electrophoresed through a $1.5 \%$ agarose formaldehyde gel. The RNA was blotted onto a nylon membrane. Lanes $1-6$ correspond to Canton-S, awdRR14, awdRR17/awdKR7,K-pn, pn, and $p n ; K-p n /+$, respectively. $|A|$ The filter was hybridized with a mixture of two cDNAs. One, pc870, hybridizes to a $1.35 \mathrm{~kb}$ transcript; the other, $p c 600$, hybridizes to the $0.8-\mathrm{kb}$ awd transcript. $(B)$ The filter was washed and hybridized with probe 2 (Fig. 4) which encodes a $0.9-\mathrm{kb}$ transcript.
It contains a single copy of the insert in its genome (I) Biggs, unpubl.). Males from this transformed line were mated to females homozygous for prune. No male progeny with the $r y^{506}\left[r y^{+} a w d^{K-p p}\right]$ chromosome were recovered (Fig. 6). This indicates that even in the presence of two copies of the $a w d^{+}$gene, one copy of $a w d^{K \cdot p n}$ is sufficient to cause a lethal interaction with prune. The 3.4-kb Sall fragment used for transformation contains two coding regions, awd and the $1.35-\mathrm{kb}$ transcript upstream of $a w d$. However, the fact that Killer of prune revertants $a w d^{R R 14}$ and $a w d^{K R 17}$ eliminate the $a w d$ mRNA without affecting the level of the $1.35-\mathrm{kb}$ mRNA (Fig. 5A) indicates that Killer of prune is a mutation in the awd gene.

\section{Nucleotide sequence of an awd cDNA}

To obtain the amino acid sequence of the awd gene product, we determined the sequence of the awd cDNA, pc600. Nucleotides $108-680$ in Figure 7 are derived from the cDNA. S1 protection studies (Dearolf et al. 1988b) and primer extension studies (data not shown) indicate the cDNA is full length. Nucleotides 1-107 in Figure 7 were derived from an $a w d^{b 3}$ genomic clone, pEM2.7a (Dearolf et al. 1988b).

The proposed cap site begins at nucleotide 105. This sequence, GGCATTC has five of seven nucleotides in common with a reported insect consensus sequence for non-heat shock genes, ATCA $/ \mathrm{G} / \mathrm{T} / \mathrm{T} / \mathrm{C} / \mathrm{T}$ ) (Hultmark et al. 1986). The size of the transcript initiating at this site, $565 \mathrm{bp}$, is consistent with the 570 -bp size determined by S1 analysis (Dearolf et al. 1988b). The polyadenylation signal AATAAA (Proudfoot and Brownlee 1976) is located at nucleotide $653,27 \mathrm{bp}$ from the actual poly(A) sequence. The site of the P-element insertion in $a w d^{b 3}$ begins at nucleotide 164. An intron of approximately $250 \mathrm{bp}$ is close to nucleotide 280 . The size of this intron was estimated from the difference in size between 


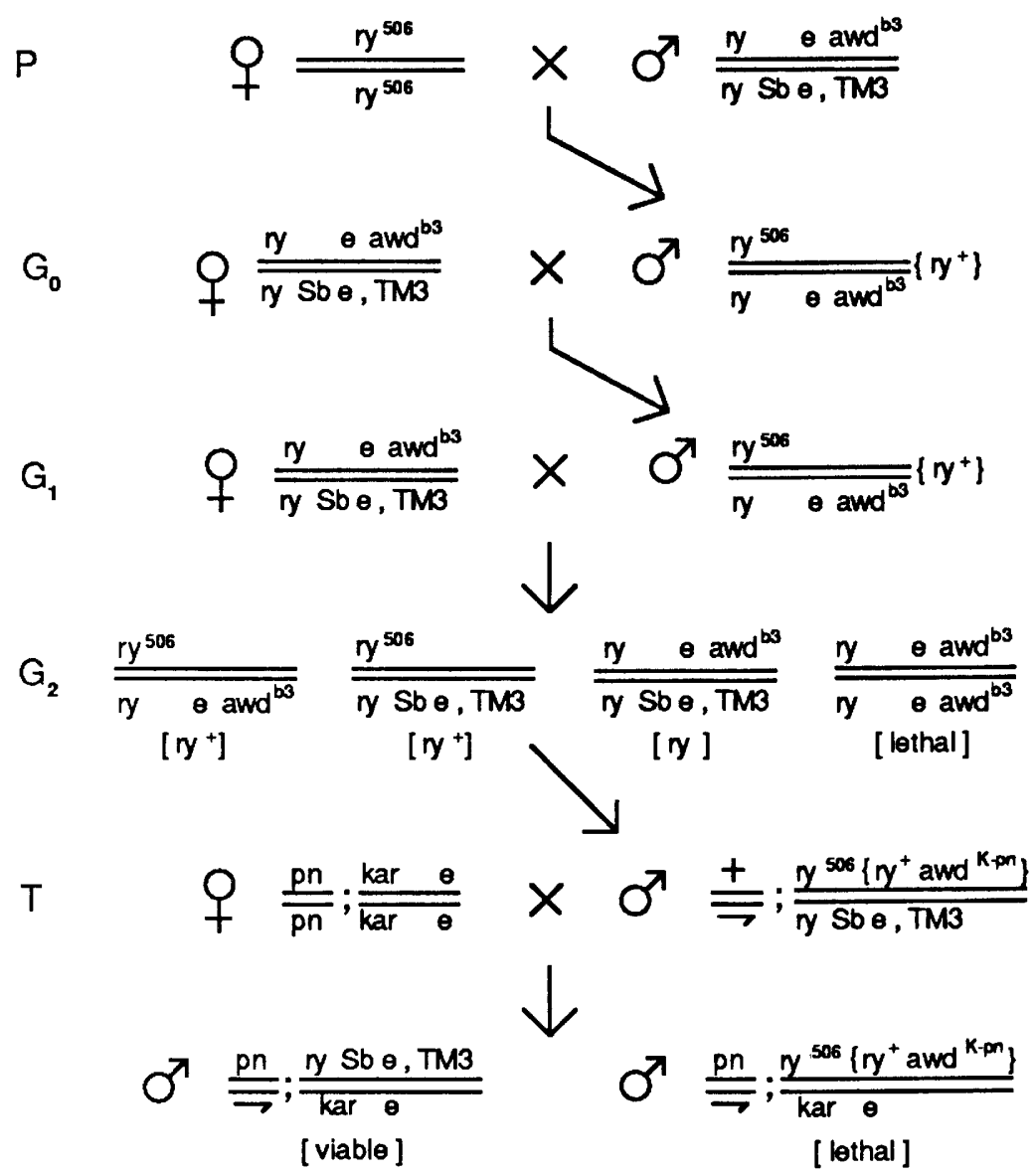

Figure 6. Germ-line transformation of Drosophila embryos with $a w d^{K-p n}$ DNA. The embryos from a cross (P) between ry/ry and ry $e a w d^{b 3} /$ $T M 3$, ry $S b$ e flies were injected with a DNA fragment containing the $K-p n$ allele of $a w d$. A 3.4-kb Sall fragment from the $K$-pn genome containing the awci gene was cloned into the Carnegie 20 transformation vector. This plasmid, along with the 'wings clipped' helper plasmid, was injected according to the method of Rubin and Spradling (1982). Subsequent crosses were carried out as indicated. The various classes of $\mathrm{G}_{2}$ progeny were examined for the segregation of the ry + phenotype to determine the chromosomal location of the insert. Some transformed lines gave $\mathrm{G}_{2}$ progeny of the ry $e a w d^{b 3} / r y e$ $a w d^{b 3}$ genotype, proving that the $K$-pn allele of awd can rescue the $a w d^{b 3}$ null allele; transformed lines which gave ry ${ }^{+} \mathrm{G}_{2}$ progeny of the ry/TM3, ry $S b$ e genotype were used for crosses to $p n$ females as shown.
cDNA restriction fragments and genomic restriction fragments. Its location was estimated by subtracting the size of the $3^{\prime}$ exon $\left(400 \mathrm{bp}\right.$ ) from the $3^{\prime}$ end of the sequence, 680 .

The awd sequence (Fig. 7) contains one continuous open reading frame. The codon usage of this reading frame is consistent with that expected for a Drosophila gene (O'Connell and Rosbash 1984). In over $90 \%$ of eukaryotic genes, translation initiates at the first AUG codon (Kozak 1984). In the awd gene, this codon is located at nucleotide 133. According to Kozak (1986), the most favorable context for initiation of translation is the sequence ACCATGG. In awd the context of the proposed initiation site is ACAATGG. If this site is used for the start of translation, the awd transcript would contain a 28-bp 5'-untranslated leader sequence and would generate a polypeptide of 153 amino acids with a molecular weight of $16-17 \mathrm{kD}$.

\section{Identification of the awd polypeptide}

We used antiserum from a rabbit immunized against an $a w d-\operatorname{trp} E$ fusion protein to identify the awd polypeptide. This antiserum reacts with two polypeptides extracted from wild-type larvae: one of $40 \mathrm{kD}$ and one of $16 \mathrm{kD}$ (Fig. 8). The origin of the $40-\mathrm{kD}$ polypeptide is unclear, but its presence is extremely useful as an in- ternal standard. Since the size predicted for the $a w d$ protein based on its cDNA sequence is $16-17 \mathrm{kD}$, we believe the $16-\mathrm{kD}$ polypeptide is the product of the awd gene. This is further supported by the absence of this $16-\mathrm{kD}$ polypeptide in $a w d^{b 3}$ homozygous larvae (Fig. 8).

Although no awd transcript is detectable in $a w d^{K R 14}$ larvae (Fig. 5), $a w d^{K R 14}$ does not cause lethality at the stage expected of a null awd allele. It causes lethality at the pharate adult stage, whereas the null allele, $a w d^{b 3}$, causes lethality at the early pupal stage. Since the protein coding region is not affected by $a w d^{K R 14}$, we considered the possibility that homozygous awd $d^{K R 14}$ larvae survived to a later stage than do homozygous $a w d^{b 3}$ larvae because they accumulate a small amount of $a w d$ protein. To examine this possibility, we compared the level of $a w d$ protein in homozygous $a w d^{K R 14}$ larvae to that of control larvae. In homozygous $a w d^{K R 14}$ larvae, the amount of the $40-\mathrm{kD}$ protein is similar to that in control larvae, but the amount of the $16-\mathrm{kD}$ protein is only $20 \%$ of that in control larvae (Fig. 9A).

To determine whether or not the awd polypeptide exists primarily as a monomer in vivo, we have fractionated an embryo extract on a gel filtration column. Preliminary experiments (J. Biggs, unpubl.) had established that the awd polypeptide is present in embryos, that it remains in the supernatant after centrifugation of a homogenate at $12,000 \mathrm{~g}$ for $15 \mathrm{~min}$, and that the antiserum 
Biggs et al. TAT TCG GGA TTT TTT TGC GGC GAA CAC ATG AAg CTC CTG ATG CTC GGC

$\mid \mathrm{CDNA} \rightarrow$ ACA ATT TTG GCA TTC TTT

$$
\uparrow^{\text {P-element }} \uparrow
$$

145 AAG GAG AGG ACT TTC ATC ATG GTC AAG CCC GAT GGC GTC CAG CGC GGG Lys Glu Arg Thr phe Ile Met Val Lys pro Asp Gly Val Gin Arg Gly CTC GTC GGC AAG ATC ATC GAg CGC TTC GAG CAG AAG GGC TTC AAG CTG Leu Val Gly Lys Ile Ile Glu Arg Phe Glu Gln Lys Gly phe Lys Leu

241 GTC GCC CTG AAG TTC ACC TGG GCC TCC AAG GAG CTG CTG GAG AAG CAC Val Ala Leu Lys phe Thr Trp Ala Ser Lys Glu Leu Leu Glu Lys His

TAC GCT GAT CTG TCC GCC CGC CCC TTC TTC CCC GGA CTC GTG AAC TAC Tyr Ala Asp Leu Ser Ala Arg Pro Phe Phe Pro Gly Leu Val Asn Tyr

337 ATG AAC TCC GGC CCC GTG GTG CCC ATG GTG TGG GAG GGT CTG AAT GT Met Asn Ser Gly Pro Val Val Pro Met Val Trp Glu Gly Leu Asn Val

GTC AAG ACC GGT CGC CAG ATG CTC GGC GCC ACC AAC CCC GCC GAC TCG Val Lys Thr Gly Arg Gln Met Leu Gly Ala Thr Asn Pro Ala Asp Ser

433 CTG CCC GGC ACC ATC CGC GGT GAC TTC TGC ATT CAG GTC GGA CGC AAC Leu Pro Gly Thr Ile Arg Gly Asp Phe Cys Ile Gln Val Gly Arg Asn

481 ATC ATC CAC GGC TCC GAT GCC GTC GAG TCT GCC GAG AAG GAG ATC GCC Ile Ile His Gly Ser Asp Ala Val Glu Ser Ala Glu Lys Glu Ile Ala

CTG TGG TTC AAC GAA AAG GAG CTG GTC ACC TGG ACC CCG GCC GCC AAG Leu Trp Phe Asn Glu Lys Glu Leu Val Thr Trp Thr Pro Ala Ala Lys

GAC TGG ATC TAC GAA TAG Asp Trp Ile Tyr Glu *

673 TAC TAT AT 680

48

96

144

192

Figure 7. Nucleotide sequence of the $a w d$ locus. The sequence was determined from the cDNA pc600 (nucleotides 108-680) and from $p E M$ 2.7c (nucleotides 1-171). The predicted 5'-capping site (nucleotides 107-114), the polyadenylation signal (nucleotides 664-669), and the 8 bp flanking the P-element insert in the $a w d^{b 3}$ allele are underlined. The start codon for the 153 amino acid open reading frame is at nucleotide 133 .

does not react with the awd polypeptide prior to denaturation. The supernatant of an embryo extract was mixed with a set of protein size standards and applied to a Bio-Gel P300 column. One-half of each fraction collected from the column was applied to each of a pair of SDS-polyacrylamide gels. One gel was stained with Coomassie brilliant blue $\mathrm{R}$ to determine the elution profile of the size standards. The other gel was used for a Western blot to determine the elution profile of the awd polypeptide. The results of this fractionation indicate that the awd polypeptide has a molecular weight of 100,000 in the native state (Fig. 10). This suggests the awd polypeptide is either part of a multisubunit protein complex or part of a multimeric protein.

Similarity of the awd predicted amino acid sequence to a subunit of cytochrome oxidase

A search of the protein database for sequences similar to the predicted awd polypeptide revealed the best fit was with a class of small cytochrome oxidase subunits represented by subunit $\mathrm{V}$ of the yeast and Neurospora crassa enzyme and subunit IV of the bovine heart enzyme. An alignment of the four sequences is shown in Figure 11. 


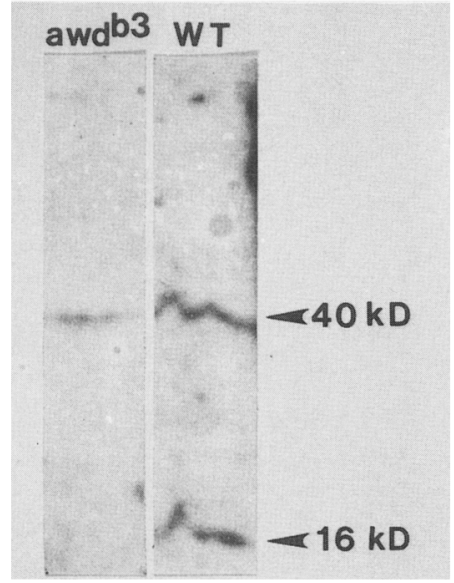

Figure 8. Western blot analysis of the level of awd protein in Canton $S$ and $a w d^{b 3}$ larvae. Third-instar larvae (approximately 1 larva/10 $\mu$ l buffer) were homogenized in SDS sample buffer, the homogenate was boiled, and $40 \mu l$ of each homogenate was loaded into one lane of a $12 \%$ SDS-polyacrylamide gel. The total larval proteins were transferred after fractionation onto nitrocellulose, reacted with awd immune serum followed by [125I]protein A (see Materials and methods).
The alignment of the first 50 amino acids of the yeast, bovine, and Neurospora cytochrome oxidase subunits is from Powers et al. (1984). In the amino-terminal twothirds of the polypeptides, $43 \%$ of the awd amino acids are identical to the amino acids found in either the yeast or the bovine cytochrome oxidase subunit. An additional $14 \%$ of the awd residues are conservative substitutions. Comparison of the amino-terminal two-thirds of yeast subunit $V$ to bovine subunit IV reveals that $21 \%$ of the residues are identical and $11 \%$ of the residues are conservative substitutions (Capaldi et al. 1986; Cumsky et al. 1987).

\section{Effect of prune and K-pn on the accumulation of the} awd protein

To provide an explanation for the lethal interaction between prune and $K$-pn, we have examined the effect of prune and K-pn on the accumulation of the awd transcript and the awd polypeptide. The awd transcript accumulates to a normal level in larvae homozygous for prune or K-pn and also in lethal male larvae which result from the cross of prune females to $K-p n$ males (Fig. 5). The $a w d$ polypeptide also accumulates to a normal level

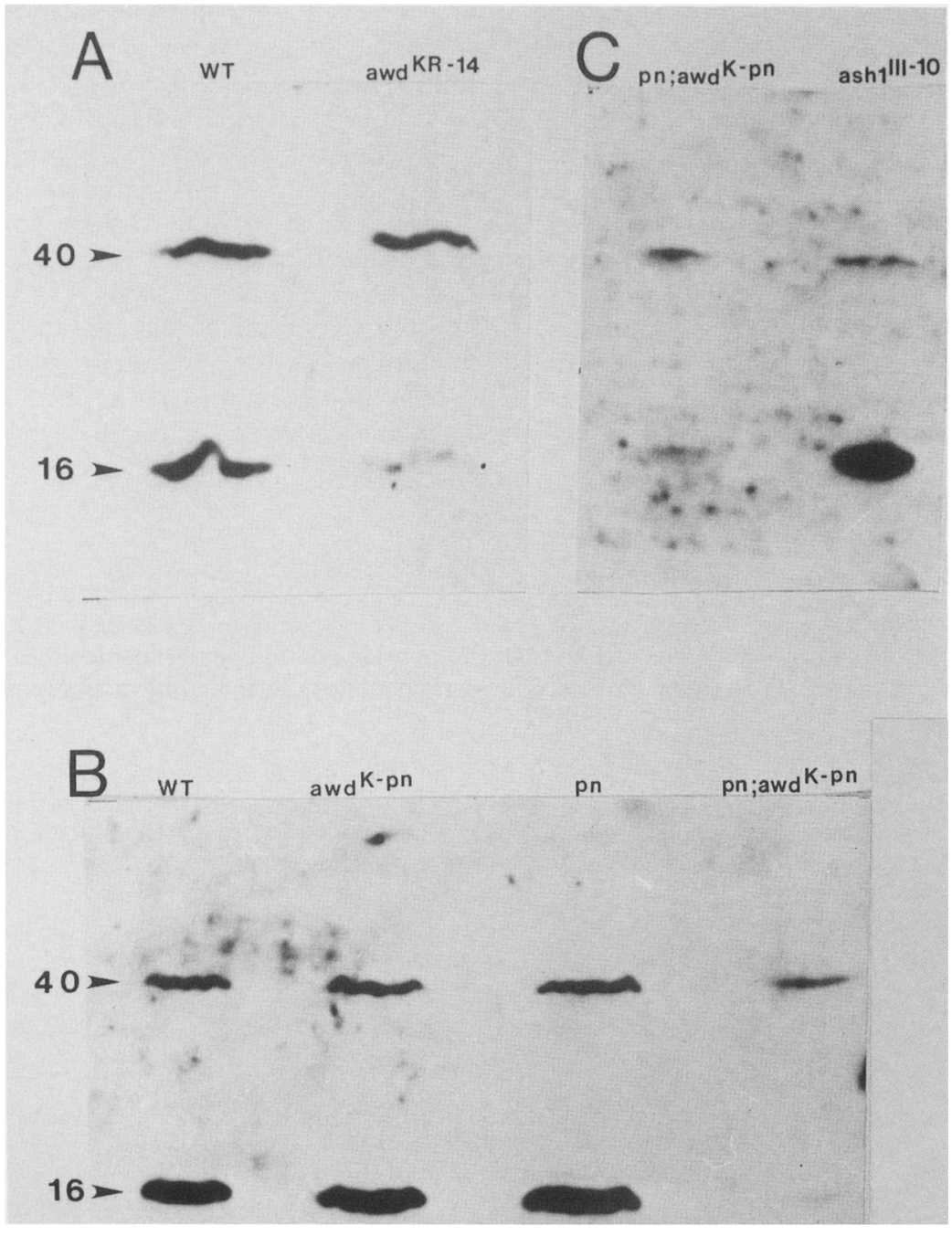

Figure 9. Western blot analysis of awd protein in mutant larvae. Methods as in Fig. 8. The genotype of the larvae used is indicated at the top of each lane. (A) (WT) Canton S; $\left(a w d^{K R \cdot 14}\right)$ larvae homozygous for $a w d^{K R-14}$. $(B)\left(a w d^{K p n}\right)$ Larvae homozygous for $a w d^{K-p n}$; (pn) larvae homozygous for $p n$; $\left(p n ; a w d^{K-p n}\right)$ male larvae hemizygous for $p n$ and heterozygous for $a w d^{K \cdot p n} .(C)$ ash $-1^{1 I-10}$ is a late larval lethal included as a control for the effects of larval death. 
Figure 10. Bio-Gel P-300 gel filtration chromatography of the awd polypeptide. The column was developed as outlined in Materials and methods. Each fraction was run as a lane on an SDS-polyacrylamide gel. The proteins were blotted onto nitrocellulose, treated with antibodies to the awd protein followed by [125I]protein A. The awd protein band on the resulting autoradiogram was scanned lane by lane using an ISCO 1312 gel scanner. Gel scanner absorbance units are plotted versus fraction number. Elution fractions of molecular weight standards are indicated.

in prune and $K$-pn larvae (Fig. 9B). However, lethal $p n ; K$ $p n /+$ larvae accumulate very little $a w d$ polypeptide (Fig. 9B/ despite their accumulation of a normal level of awd transcript. This low level of awd polypeptide in lethal $p n ; K-p n$ larvae is not a general property of larval lethality. For example, the level of $a w d$ polypeptide in an unrelated larval lethal mutant is comparable to wild type (Fig. 9C).

\section{Discussion}

Evidence that K-pn is a mutation in the awd gene

All 12 of the gamma-ray-induced $K$-pn revertants we recovered failed to complement the lethality of $a w d^{b 3}$. We

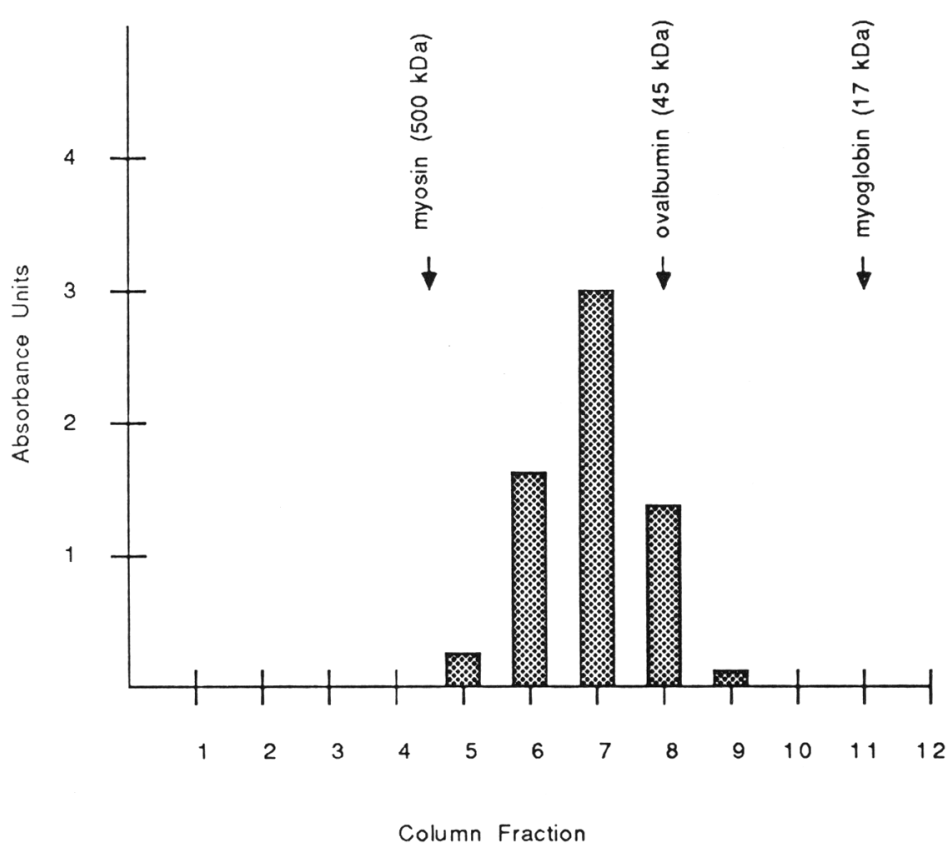

examined the nature of three cytologically normal revertants at the molecular level. One of the three, $a w d^{K R 7}$, is a deletion that removes sequences flanking the awd gene in addition to the entire awd gene (Fig. 4). Another, $a w d^{K R 17}$, is missing 800 bp which include the $3^{\prime}$-transcribed region of the awd gene and sequences flanking a downstream gene (Fig. 4). The $a w d^{K R 17}$ mutation eliminates the accumulation of both the $0.8-\mathrm{kb}$ awd and the 0.9-kb downstream transcripts (Fig. 5).

The most significant of the $K$-pn revertants is $a w d^{K R 14}$ because it only affects the awd transcript. No awd transcript was detected in third-instar $a w d^{K R 14}$ homozygous larvae (Fig. 5). The $a w d^{K R 14}$ mutation occurred in the 5'nontranscribed region of the awd gene (Figs. 3 and 4).
Figure 11. Sequence alignments between the awd protein and cytochrome oxidase subunits. The sequence of beef heart cytochrome oxidase subunit IV is taken from Capaldi et al. (1986). The sequences of the two forms of yeast cytochrome oxidase subunit $V$ are taken from Cumsky et al. (1987). The sequence of the amino terminus of $N$. crassa cytochrome oxidase subunit $\mathrm{V}$ is taken from Power et al. (1984). Amino acids that are identical or similar are shaded.

Bovine
Neurospora
Yeast 1
Yeast 2
Drosophila

Bovine
Yeast 1
Yeast 2
Drosophila
Bovine
Yeast 1
Yeast 2
Drosophila

Bovine
Yeast 1
Yeast 2
Drosophila


Thus, $a w d^{R R 14}$ reverted $K$-pn and caused a recessive lethal awd allele by eliminating a single transcript, the awd transcript. We confirmed that $K-p n$ is an allele of awd by germ-line transformation (Fig. 6). Henceforth, we refer to $K-p n$ as $a w d^{K-p n}$.

The phenotype of $a w d^{R R 14}$ homozygotes and $a w d^{b 3 /}$ $a w d^{K R 14}$ transheterozygotes is less severe than that of $a w d^{b 3}$ homozygotes. This less severe phenotype suggested that $a w d^{K R 14}$ is not a null allele. Southern and Northern blot analyses showed that $a w d^{K R 14}$ affects an upstream regulatory element of the $a w d$ gene. Although we were not able to detect accumulation of the awd transcript in $a w d^{K R 14}$ homozygous larvae (Fig. 5), we were able to detect a small amount of $a w d$ polypeptide (Fig. 9A). We believe the reversion of the $K$-pn phenotype that occurred in $a w d^{R R 14}$ to be a consequence of its reduced accumulation of the abnormal $a w d^{K-p n}$ gene product. The amount of $a w d^{K \cdot p n}$ polypeptide in $a w d^{K R 14 /}$ $a w d^{K R 14}$ homozygous larvae is adequate to support development until the pharate adult stage, but the amount made in $a w d^{K R 14} / a w d^{+}$heterozygous larvae is too low to cause the lethal interaction with $p n$.

\section{Interaction of pn with awd $\mathrm{d}^{\mathrm{K}-\mathrm{pn}}$}

The $a w d^{K-p n}$ mutation does not alter the level of $a w d$ RNA (Fig. 5) or awd polypeptide (Fig. 8C). Mutations in the pn gene also do not alter the level of awd RNA (Fig. 5) or awd polypeptide (Fig. 9C). Lethal pn; awd $d^{K-p n / a w d+}$ larvae also contain the normal level of awd RNA (Fig. 5), but they accumulate very little awd polypeptide (Fig. $9 \mathrm{Cl}$. These larvae are heterozygous for a wild-type awd allele, so the interaction of $p n$ and $a w d^{K-p n}$ reduces the accumulation of both the $a w d^{K-p n}$ polypeptide and the $a w d^{+}$polypeptide. It appears that a certain amount of the $a w d^{K-p n}$ abnormal polypeptide is required for the lethal interaction with $p n$ to occur. Male larvae with the genotype $p n ; a w d^{K-p n} / a w d^{+}$would be expected to have a $1: 1$ ratio of mutant to wild-type polypeptide and they die at the beginning of the third-instar larval stage. Male larvae with the genotype $p n ; a w d^{K-p n} a w d^{+} / a w d^{+}($derived by germ-line transformation; Fig. 6) would be expected to have a $1: 2$ ratio of mutant to wild-type polypeptide and they survive until the end of the third-instar larval stage. Male larvae with the genotype $p n ; a w d^{K R 14 /}$ $a w d^{+}$would be expected to have a $1: 5$ ratio of mutant to wild-type polypeptide, because the $a w d^{R R 14}$ allele produces only $20 \%$ as much of the $a w d^{K-p n}$ polypeptide as does the $a w d^{K-p n}$ allele (Fig. 9A) and they are viable. These results suggest that for the lethal interaction with prune to occur, greater than $17 \%$ but as little as $33 \%$ of the total awd polypeptide must be of the $a w d^{K-p n}$ form. The evidence from gel-filtration chromatography (Fig. 10 ) indicates that the $16-\mathrm{kD} a w d^{+}$polypeptide is part of a $100-\mathrm{kD}$ protein. Perhaps there are two or more awd polypeptides in each $100-\mathrm{kD}$ protein, and this protein fails to form or is unstable in a pn organism if one or more of those $a w d$ polypeptides is $a w d^{K-p n}$.
The relationship between the pn product and the $\mathrm{pn}_{\text {; }}$ awd $\mathrm{d}^{\mathrm{K}-\mathrm{pn}}$ interaction

The primary product of the pn gene is not yet known. pn mutations affect the level of activity of the enzyme GTP cyclohydrolase. This enzyme catalyzes the first step in pteridine biosynthesis and is the product of the Punch locus (Mackay and O'Donnell 1983). The eye-color phenotype of $p n$ mutations is caused by a reduction in the concentration of red pteridine pigments. The interaction of $p n$ with $a w d^{K-p n}$ is quite specific; $a w d^{K-p n}$ has no phenotype in combination with other mutations that cause altered accumulations of pteridines (Sturtevant 1956). Using gynandromorphs to do fate mapping, Orevi and Falk (1975) concluded that the lethal interaction has a focus in the ventral region of embryos that gives rise to mesodermal structures and the nervous system. They also found the focus was domineering, i.e., patches of cells that were hemizygous for $p n$ and heterozygous for $a w d^{K-p n}$ and thus genotypically lethal could cause the lethality of other cells that were heterozygous for $p n$ and thus genotypically nonlethal. Since awd is expressed in the nervous system and in a cell-autonomous fashion (Dearolf et al. 1988a), this suggests that the lethal interaction could be mediated by a diffusible molecule that is released by cells of the nervous system affected by the pn mutation (Orevi and Falk 1975).

Similarity of the awd amino acid sequence to that of a cytochrome oxidase subunit

The predicted amino acid sequence and observed molecular weight of the awd polypeptide is similar to one of the subunits of the mitochondrial enzyme, cytochrome oxidase. However, we do not believe that $a w d$ is a subunit of cytochrome oxidase. First, in cell fractionation experiments, we can detect the $a w d$ polypeptide only in the postmitochondrial supernatant, not in mitochrondria. Second, the predicted amino acid sequence of the awd polypeptide does not contain a signal or leader peptide as do both of the yeast subunit $\mathrm{V}$ polypeptides (Cumsky et al. 1987). Third, denatured purified yeast cytochrome oxidase does not cross-react with antiserum raised against an awd fusion protein (J. Biggs, unpubl.). Fourth, despite the considerable similarity of the awd sequence to that of the yeast and bovine cytochrome oxidase subunits, plots of their relative hydropathicity (Kyte and Doolittle 1982) indicate that awd has a different pattern than do the cytochrome oxidase subunits, which have patterns strikingly similar to each other (data not shown). Perhaps the awd polypeptide plays a role in the protein of which it is a subunit, that is analogous to the role of subunit $\mathrm{V}$ in yeast cytochrome oxidase.

\section{Materials and methods}

Drosophila strains

The $c a K-p n$ and $p n ;$ kar $e$ stocks were obtained from the Bowling Green Stock Center. The mwh red e, Canton $S$ and $y$; 
Gl DTS $(3) 2 / \mathrm{y}^{+}, T M 3 \mathrm{Sb}$ Ser stocks are maintained in this laboratory. The $a w d^{b 3}$ allele (Dearolf et al. 1988a) was generated in a $m w h$ red $e$ chromosome, by a hybrid dysgenic cross and maintained as mwh red e awd ${ }^{b 3} / T M 3, S b$ Ser or as $y$; mwh red $e$ $a w d^{b 3} / y^{+}, T M 3 S b S e r$. To generate $K$-pn revertants, ca $K$-pn males were irradiated with gamma rays from the cesium source of a Gammator B (Isomedix Inc., Parsippany, New Jersey) with a total dose of $4000 \mathrm{R}$. The irradiated males were then mated to $p n$; kar $e$ females. The $p n$ male progeny of this cross represent putative $K$-pn revertants. The revertants were maintained as $y$; ca $a w d^{K R} / y^{+}, T M 3 S b$ Ser. For a description of markers and balancers used in this report see Lindsley and Grell (1968).

\section{Stage of lethality}

The stage of lethality was determined for revertant-bearing chromosomes as homozgotes and as transheterozygotes with each other and with $m$ wh red e awd $d^{b 3}$. Eggs were collected from balanced lethal stocks or from crosses between different stocks. All of the larvae from a vial were harvested and the number of homozygous (or transheterozygous) and heterozygous larvae was counted. The homozygous or transheterozygous larvae could be distinguished from heterozygous larvae because they expressed the $y$ larval phenotype. The homozygous or transheterozygous larvae were placed in fresh vials and their further development was observed. Some were dissected to examine their imaginal disc phenotype. Lethal $p n ; a w d^{K-p n} / a w d^{+}$male larvae were produced by crossing homozygous $p n$ females to homozygous $a w d^{K-p n}$ males. Male larvae were recognized by the presence of testes.

\section{Genomic Southern blots}

Flies were homogenized in $0.1 \mathrm{M}$ Tris- $\mathrm{HCl}(\mathrm{pH} 8.0), 50 \mathrm{~mm}$ EDTA, $1 \%$ sarcosyl, then $\mathrm{NaCl}$ and Proteinase $\mathrm{K}$ were added to final concentrations of $0.1 \mathrm{M}$ and $0.1 \mathrm{mg} / \mathrm{ml}$, respectively. The homogenate was incubated at $37^{\circ} \mathrm{C}$ for $1 \mathrm{hr}$, then extracted once with $1: 1 \mathrm{phenol} / \mathrm{chloroform}$. The DNA in the aqueous phase was precipitated with ethanol, and the pellet resuspended in $0.1 \times$ SSC. RNase was added (to $10 \mu \mathrm{g} / \mathrm{ml}$ ), and the sample incubated $30 \mathrm{~min}$ at $37^{\circ} \mathrm{C}$; proteinase $\mathrm{K}$ was added (final concentration of $0.1 \mathrm{mg} / \mathrm{ml}$ ) and the incubation continued for $1 \mathrm{hr}$. The sample was extracted with phenol/chloroform and precipitated, and the pellet was resuspended in TE $[10 \mathrm{mM}$ Tris- $\mathrm{HCl}$ (pH 7.5), 1 mM EDTA]. The DNA was digested with restriction enzymes, fractionated on $0.8-1.5 \%$ agarose gels, blotted onto nylon membranes with $20 \times$ SSC, fixed by UV-irradiation, and hybridized to radioactive DNA probes. A solution of $5 \times$ SSC, $5 \times$ Denhardt's solution, $0.1 \%$ SDS, and $250 \mu \mathrm{g} / \mathrm{ml}$ denatured calf thymus DNA was used for prehybridization and hybridization at $65^{\circ} \mathrm{C}$. Filters were washed for $30 \mathrm{~min}$ at $65^{\circ} \mathrm{C}$ in $2 \times \mathrm{SSC}$ with one change of solution, for $30 \mathrm{~min}$ at $65^{\circ} \mathrm{C}$ in $2 \times \mathrm{SCC}$, $0.1 \% \mathrm{SDS}$, and for $10 \mathrm{~min}$ at $65^{\circ} \mathrm{C}$ in $0.1 \times \mathrm{SSC}$. The filters were blotted dry and autoradiographed.

\section{Northern analysis}

Total RNA was isolated by a modification of the method of Thireos et al. (1980). Adults or larvae were homogenized in a $1: 1$ mixture of phenol and RNA extraction buffer [10 mM Tris$\mathrm{HCl}$ ( $\mathrm{pH} 7.4$ ), $100 \mathrm{~mm} \mathrm{NaCl}, 1 \mathrm{~mm}$ EDTA, and $0.5 \% \mathrm{SDS}$ ); the aqueous phase was extracted several more times with a $1: 1$ mixture of phenol/chloroform. RNA was precipitated from the aqueous phase with 2.5 volumes of ethanol overnight at $20^{\circ} \mathrm{C}$ and pelleted by spinning for $40 \mathrm{~min}$ at $16,000 \mathrm{~g}$. The RNA was washed with $70 \%$ ethanol and resuspended in water. For
Northern analysis, RNA samples were prepared in running buffer plus $2.2 \mathrm{M}$ formaldehyde and $50 \%$ (vol/vol) formamide, and heat-denatured $5 \mathrm{~min}$ at $60^{\circ} \mathrm{C}$. The RNA was fractionated on agarose gels containing $2.2 \mathrm{M}$ formaldehyde [running buffer: $20 \mathrm{mM}$ MOPS (pH 7.0), $5 \mathrm{~mm}$ sodium acetate, $1 \mathrm{~mm}$ EDTA]. The RNA was blotted onto a nylon membrane with $20 \times$ SSC and hybridized to radiolabeled probes. The prehybridization and hybridization solution was $5 \times \mathrm{SSC}, 50 \%$ (vol/vol) formamide, $5 \times$ Denhardt's solution, $0.1 \%$ SDS, and $250 \mu \mathrm{g} / \mathrm{ml}$ denatured calf thymus DNA. The filters were washed three times in $2 \times$ SSC, $0.1 \%$ SDS at room temperature, and twice in $0.1 \times$ SSC and $0.1 \%$ SDS at $50^{\circ} \mathrm{C}$.

\section{Germ-line transformation}

Embryos were injected according to the method of Rubin and Spradling (1982) with a plasmid containing the awd gene cloned from a $K$-pn genomic library. The embryos injected were the progeny of a cross between homozygous ry females and males of the genotype ry $e a w d^{b 3} / T M 3$, ry $e S b$ (Fig. 6). Injected embryos that gave rise to flies with a $r y^{+}$phenotype $\left(\mathrm{G}_{0}\right.$ individuals) were mated to flies with the genotype ry e awd $d^{b 3} / T M 3$, ry $e S b$. To establish transformed lines, $\mathrm{G}_{1}$ individuals with a $\mathrm{ry}^{+}$phenotype were mated to flies with the genotype ry $e$ $a w d^{b 3} / T M 3$, ry $e S b$. By examining the progeny of this cross and comparing the segregation of the $r y^{+}$phenotype to that of the $e$ and $S b$ phenotypes, it was possible to determine that transformed lines carried the $a w d^{K-p n}$ insert on the third chromsome. To test whether such inserts confer the $K$-pn phenotype, females homozygous for prune were mated to transformed males with the genotype $r y^{506}\left[r y^{+} a w d^{K-p n}\right] / T M 3, r y^{506} e S b$. If the insert confers the $K$-pn phenotype, then no male progeny with the genotype $p n ; r y^{506}\left[r y^{+} a w d^{K-p n}\right] /+$ should survive.

\section{Gel filtration chromatography}

Approximately 5.0 grams of Drosophila embryos were homogenized in $5.0 \mathrm{ml}$ of buffer as used by Arrigo (1987) for subcellular fractionation [10 mM Tris (pH 7.4), $10 \mathrm{mM} \mathrm{NaCl}, 5 \mathrm{~mm} \mathrm{MgCl}_{2}$, $0.2 \%$ Triton X-100, $1 \mathrm{~mm} \beta$-mercaptoethanol, $1 \mathrm{~mm}$ phenylmethylsulfonylfluoride]. Homogenization was performed at $0-4^{\circ} \mathrm{C}$ with a Wheaton glass homogenizer (B pestle). The homogenate was centrifuged at $12,000 \mathrm{~g}$ for $15 \mathrm{~min}$ to pellet unbroken cells, nuclei, and large organelles. This supernatant was lyophilized to one-tenth starting volume and loaded onto a BioGel P300 column. Proteins were eluted from the column with $10 \mathrm{~mm}$ Tris (pH 7.4). Fractions were collected (1 ml), lyophilized to dryness, resuspended in $150 \mu$ l of SDS sample buffer, boiled for $5 \mathrm{~min}$, and electrophoresed on $12 \%$ SDS-polyacrylamide gels. The gels were either stained with Coomassie brilliant blue $\mathrm{R}$ or used for Western blots with antiserum from a rabbit immunized against an awd-trp $E$ fusion protein.

\section{Immunological methods}

An AluI fragment of an awd cDNA (pc600) containing codons $48-139$ was inserted into the SmaI site of the $p A T H-2$ expression vector (T.J. Koemer, unpubl.). The fusion protein produced by this construct contains $13 \mathrm{kD}$ of $a w d$ protein fused to the carboxyl terminus of the Escherichia coli trp E protein. This fusion protein was isolated from a preparative SDS-polyacrylamide gel, ground to a powder in liquid nitrogen and resuspended in $50 \%(\mathrm{vol} / \mathrm{vol})$ Freund's adjuvant. Once a week for 3 weeks $0.2 \mathrm{ml}$ of this mixture was injected into a New Zealand white rabbit. A final boost injection was given 2 weeks later. One week after the last injection, about $30 \mathrm{ml}$ of blood was collected 
and allowed to clot overnight at $4^{\circ} \mathrm{C}$. After removing the clot, the remaining liquid was centrifuged at $10,000 \mathrm{rpm}$ for $10 \mathrm{~min}$ to remove any remaining cells from the serum. This serum was used for Western blots.

Whole larvae (40) were homogenized in $0.5 \mathrm{ml}$ of SDS sample buffer $[20 \%$ glycerol, $3 \%$ SDS, $3 \% \beta$-mercaptoethanol, $5 \mathrm{~mm}$ Tris- $\mathrm{HCl}$ (pH 7.4)\}. The homogenate was boiled for 5-10 min and $40 \mu \mathrm{l}$ was loaded into each lane of an SDS-polyacrylamide gel $\{3.5 \%$ stacking gel; $12 \%$ separating gel). After fractionation, the larval proteins on the gel were transferred to a sheet of nitrocellulose by electroblotting for $2 \mathrm{hr}$ at $200 \mathrm{~mA}$ in transfer buffer (20\% methanol, $25 \mathrm{~mm}$ Tris base, $192 \mathrm{~mm}$ glycine). The nitrocellulose was blocked with a solution of $5 \%$ powdered nonfat milk, $0.9 \% \mathrm{NaCl}, 10 \mathrm{~mm}$ Tris- $\mathrm{HCl}\langle\mathrm{pH} 7.4\}$, and $0.04 \%$ azide for $2 \mathrm{hr}$ at $4^{\circ} \mathrm{C}$. Reactions with antiserum and [125I]protein A were performed in a solution of $2 \%$ powdered nonfat milk, $150 \mathrm{~mm} \mathrm{NaCl}, 5 \mathrm{~mm}$ EDTA, $50 \mathrm{~mm}$ Tris- $\mathrm{HCl}$ (pH 7.4), $0.25 \%$ gelatin, $0.05 \% \mathrm{NP}-40$, and $0.04 \%$ azide. After the reactions the filter was washed for $1 \mathrm{hr}$ in four changes of $1.0 \mathrm{M} \mathrm{NaCl}, 0.4 \%$ sarcosyl, $5 \mathrm{~mm}$ EDTA, $50 \mathrm{~mm}$ Tris- $\mathrm{HCl}$ ( $\mathrm{pH} 7.4$ ), $0.25 \%$ gelatin, and $0.04 \%$ azide. The filter was rinsed with water, blotted dry, and autoradiographed.

\section{DNA sequencing}

The cDNA clone pc600 was sequenced in both directions by the method of Maxam and Gilbert (1980). The mutant genomic DNA subclone $p E c 06.2$ from the HindIII site of the inserted P element to beyond the presumed 5 ' end of the awd transcription unit was also sequenced. Dideoxy sequencing (Sanger et al. 1977) of pc600 resolved ambiguities near each of the termini of the cDNA clone.

\section{Acknowledgments}

This work was supported by a grant to A.S. from the National Institutes of Health. J.B. was supported by a postdoctoral fellowship from the National Institutes of Health. We would like to thank T.J. Koerner for the use of the $p A T H$ plasmids which he constructed, our colleagues in Douglas Fambrough's lab for instruction in immunological methods, and Karen Drummey for isolating some $K-p n$ revertants.

\section{Note}

Sequence data presented in Figure 7 have been submitted to the EMBL/GenBank Data Libraries under accession number Y00226.

\section{References}

Arrigo, A. 1987. Cellular localization of hsp23 during Drosophila development and following subsequent heat shock. Dev. Biol. 122: 39-48.

Capaldi, R.A., D. Gonzalez-Halphen, and S. Takamiya. 1986. Sequence homologies and structural similarities between the polypeptides of yeast and beef heart cytochrome $c$ oxidase. FEBS 207: 11-17.

Cumsky, M.G., C.E. Trueblood, C. Ko, and R.O. Poyton. 1987. Structural analysis of two genes encoding divergent forms of yeast cyctochrome $C$ oxidase subunit V. Mol. Cell. Biol. 7: 3511-3519.

Dearolf, C., E. Hersperger, and A. Shearn. 1988a. Developmental consequences of $a w d^{b 3}$, a cell-autonomous lethal mutation of Drosophila induced by hybrid dysgenesis. Dev. Biol. 129: 159-168.
Dearolf, C., N. Tripoulas, J. Biggs, and A. Shearn. 1988b. Molecular consequences of $a w d^{b 3}$, a cell-autonomous lethal mutation of Drosophila induced by hybrid dysgenesis. Dev. Biol. 129: $169-178$.

Hultmark, D., R. Klemenz, and W. Gehring. 1986. Translational and transcriptional control elements in the untranslated leader of the heat shock gene hsp22. Cell 44: 429-438.

Kozak, M. 1984. Compilation and analysis of sequences upstream from the translational start site in eukaryotic mRNAs. Nucleic Acids Res. 12: 857-872.

. 1986. Point mutations define a sequence flanking the AUG initiator codon that modulates translation by eukaryotic ribosomes. Cell 44: 283-292.

Kyte, J. and R.F. Doolittle. 1982. A method for displaying the hydropathic character of a protein. J. Mol. Biol. 157: 105132.

Lifschytz, E. and R. Falk. 1969. A genetic analysis of the Killerprune $(K-p n)$ locus of Drosophila melanogaster. Genetics 62: $353-358$.

Lindsley, D.L. and E.H. Grell. 1968. Genetic variations of Drosophila melanogaster. Carnegie Inst. Wash. Publ. 627.

Mackay, W.J. and J.M. O'Donnell. 1983. A genetic analysis of the pteridine biosynthetic enzyme, guanosine triphosphate cyclohydrolase, in Drosophila melanogaster. Genetics 105: $35-53$.

Maxam, A.M. and W. Gilbert. 1980. Sequencing end-labeled DNA with base-specific chemical cleavages. In Methods in enzymology (ed. L. Grossman and K. Moldave), vol. 65, pp. 497-559. Acedemic Press, New York.

O'Connell, P. and M. Rosbash. 1984. Sequence, structure, and codon preference of the Drosophila ribosomal protein 49 gene. Nucleic Acids Res. 12: 5495-5513.

Orevi, N. and R. Falk. 1974. The lethal interaction between the genes prune $(p n)$ and Killer of prune $(K-p n)$ in Drosophila melanogaster. Archiv. Genetik. 47: 172-183.

- 1975. Temperature-sensitive prune $(p n)$ mutations of Drosophila melanogaster. Mutation Res. 33: 193-200.

Proudfoot, N.J. and G.G. Brownlee. 1976. $3^{\prime}$ non-coding region sequences in eukaryotic messenger RNA. Nature 263: 211214.

Power, S.D., M.A. Lochrie, and R.O. Poyton. 1984. The nuclear coded subunits of yeast cytochrome $c$ oxidase. J. Biol. Chem. 259: 6575-6578.

Rubin, G.M. and A.C. Spradling. 1982. Genetic transformation of Drosophila transposable element vectors. Science 218: $348-353$.

1983. Vectors for P-element-mediated gene transfer in Drosophila. Nucleic Acids Res. 11: 6341-6351.

Sturtevant, A.H. 1956. A highly specific complementary lethal system in Drosophila melanogaster. Genetics 41: 118-123.

Sanger, F., S. Nicklen, and A.R. Coulson. 1977. DNA sequencing with chain-terminating inhibitors. Proc. Natl. Acad. Sci. 74: 5463-5467.

Thireos, G., R. Griffin-Shea, and F.C. Kafatos. 1980. Untranslated mRNA for a chorion protein of Drosophila melanogaster accumulates transiently at the onset of specific gene amplification. Proc. Natl. Acad. Sci. 77: 5789-5793. 


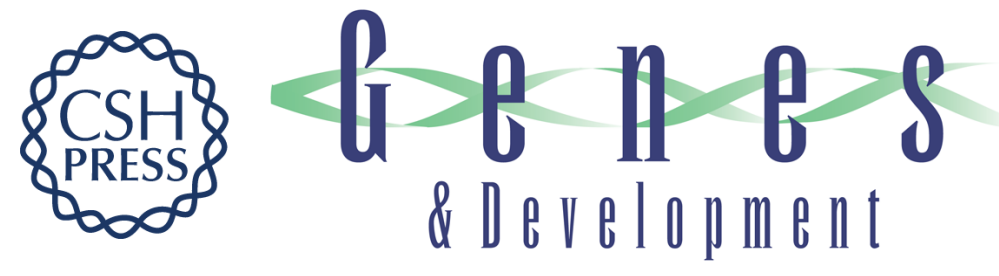

\section{Analysis of the lethal interaction between the prune and Killer of prune mutations of Drosophila.}

J Biggs, N Tripoulas, E Hersperger, et al.

Genes Dev. 1988, 2:

Access the most recent version at doi:10.1101/gad.2.10.1333

References This article cites 21 articles, 8 of which can be accessed free at:

http://genesdev.cshlp.org/content/2/10/1333.full.html\#ref-list-1

License

Email Alerting

Service

Receive free email alerts when new articles cite this article - sign up in the box at the top right corner of the article or click here.

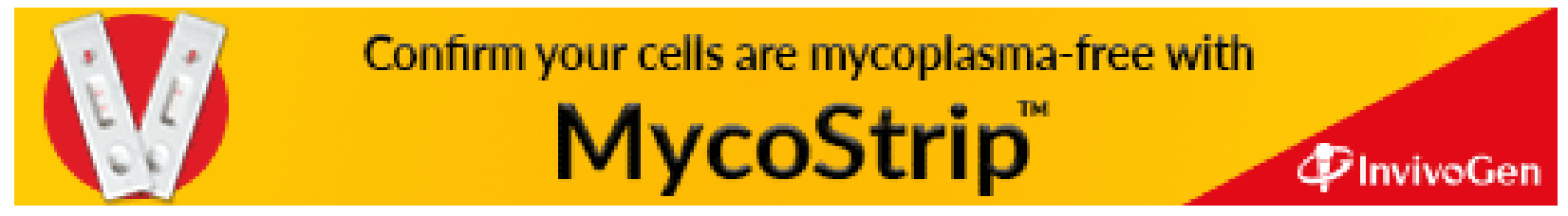

